\title{
One-Pot Template-Free Hydrothermal Synthesis of Monoclinic BiVO 4 Hollow Microspheres and Their Enhanced Visible-Light Photocatalytic Activity
}

\author{
Bei Cheng, ${ }^{1}$ Wenguang Wang, ${ }^{1}$ Lei Shi, ${ }^{1}$ Jun Zhang, ${ }^{1}$ Jingrun Ran, ${ }^{1}$ and Huogen $\mathbf{Y u}^{2}$ \\ ${ }^{1}$ State Key Laboratory of Silicate Materials for Architectures, Materials College, Wuhan University of Technology, 122 Luoshi Road, \\ Wuhan 430070, China \\ ${ }^{2}$ Department of Chemistry, School of Science, Wuhan University of Technology, Wuhan 430070, China
}

Correspondence should be addressed to Bei Cheng, chengbei2003@yahoo.com.cn

Received 24 October 2011; Accepted 4 November 2011

Academic Editor: Baibiao Huang

Copyright ( $\odot 2012$ Bei Cheng et al. This is an open access article distributed under the Creative Commons Attribution License, which permits unrestricted use, distribution, and reproduction in any medium, provided the original work is properly cited.

\begin{abstract}
Monoclinic-phase $\mathrm{BiVO}_{4}$ hollow microspheres with diameters of about 2-4 $\mu \mathrm{m}$ have been successfully fabricated in high yield by a one-pot template-free hydrothermal route. The reaction duration and urea concentration are shown to play important roles in the formation of the $\mathrm{BiVO}_{4}$ hollow microspheres. X-ray diffraction, scanning electron microscopy, nitrogen adsorption-desorption isotherms, fourier transform infrared spectrometry, and UV-visible diffuse reflectance spectroscopy are used to characterize the products. The results show that all the as-prepared $\mathrm{BiVO}_{4}$ samples have monoclinic phase structure and exhibit good crystallinity. A formation mechanism for the $\mathrm{BiVO}_{4}$ hollow spherical structure via a localized Ostwald ripening is proposed based on the experimental observations. In addition, studies of the photocatalytic properties by exposure to visible light irradiation demonstrate that the as-obtained $\mathrm{BiVO}_{4}$ hollow spheres show potential photocatalytic application. Hydroxyl radicals $\left(\bullet^{\bullet} \mathrm{OH}\right)$ are not detected on the surface of visible-light-illuminated $\mathrm{BiVO}_{4}$ by the photoluminescence technique, suggesting that ${ }^{\circ} \mathrm{OH}$ is not the dominant photooxidant and photogenerated hole could directly take part in photocatalytic reaction. The prepared $\mathrm{BiVO}_{4}$ hollow spheres are also of great interest in pigment, catalysis, separation technology, biomedical engineering, and nanotechnology.
\end{abstract}

\section{Introduction}

In recent years, hollow micro/nanostructures have attracted considerable attention because of their novel physicochemical properties that differ markedly from those of bulk materials and potential applications such as nanoscale chemical reactors, efficient catalysis, drug-delivery carriers, low dielectric constant materials, acoustic insulation, and photonic building blocks [1-5]. Conventional methods for the preparation of hollow spheres usually require removable or sacrificial templates, including hard ones [6-9] or soft ones [10-14] to direct the formation of inorganic nanoparticles on their surfaces via adsorption or chemical reactions. However, use of templates usually suffers from disadvantages related to high cost and tedious synthetic procedures, which may prevent them from being used in large-scale applications. Compared with these methods involving multistep procedures, a one-pot template-free method for the con- trolled preparation of hollow nanostructures with rationally designed parameters is highly attractive [15]. Currently, onepot template-free methods for hollow structures have been developed mainly based on direct solid evacuation arising from Ostwald ripening, the Kirkendall effect, or chemically induced self-transformation [16-19].

Bismuth vanadate $\left(\mathrm{BiVO}_{4}\right)$, which has been recognized as an effective visible-light photocatalyst for photocatalytic $\mathrm{O}_{2}$ evolution from aqueous $\mathrm{AgNO}_{3}$ solutions, but also for photocatalytic degradation of organic pollutants under visiblelight irradiation, has received significant attention [20-27]. On the other hand, the properties of $\mathrm{BiVO}_{4}$ are strongly dependent on its morphology and microstructure [24, 26, 28-33]. According to previous reports, $\mathrm{BiVO}_{4}$ appears in three main crystalline phases: monoclinic scheelite, tetragonal zircon, and tetragonal scheelite [34-36]. Among the above three crystal phase, monoclinic $\mathrm{BiVO}_{4}$ is the best visible-light-driven photocatalyst for the degradation of 
organic pollutants and $\mathrm{O}_{2}$ production from water splitting due to the transition from a valence band formed by $\mathrm{Bi}_{6 \mathrm{~s}}$ or a hybrid orbital of $\mathrm{Bi}_{6 \mathrm{~s}}$ and $\mathrm{O}_{2 \mathrm{p}}$ to a conduction band of V3d and its narrow band gap (ca. $2.4 \mathrm{eV}$ ), while the photocatalytic activity of tetragonal $\mathrm{BiVO}_{4}$ is negligible [28]. Moreover, $\mathrm{BiVO}_{4}$ powders with various morphologies have been synthesized through different templating routes. For example, Yin and coworkers have synthesized monoclinic $\mathrm{BiVO}_{4}$ hollow spheres with a size of about $700 \mathrm{~nm}$ by employing colloidal carbon spheres (CCSs) as hard templates [37]. Recently, by using mesoporous silica KIT-6 as a hard template, $\mathrm{Yu}$ and coworkers synthesized monoclinic $\mathrm{BiVO}_{4}$ ordered mesoporous nanocrystals [38]. Microspheric and lamellar $\mathrm{BiVO}_{4}$ powders were selectively prepared through a hydrothermal process by using cetyltrimethylammonium bromide (CTAB) as a template-directing reagent [39]. However, the template-assisted method not only increased the product cost but also made it more difficult to scale up production due to its complexity and the capability of a template. The template-free synthesis of well-crystallized monoclinic $\mathrm{BiVO}_{4}$ hollow spheres still remains a great challenge.

In this work, we fabricate monoclinic $\mathrm{BiVO}_{4}$ hollow microspheres by a one-pot template-free hydrothermal method using $\mathrm{NH}_{4} \mathrm{VO}_{3}$ and $\mathrm{Bi}\left(\mathrm{NO}_{3}\right)_{3}$ as precursors and urea as additive at $180^{\circ} \mathrm{C}$ for $24 \mathrm{~h}$. The influence of urea concentration on the morphology and photocatalytic activity of $\mathrm{BiVO}_{4}$ is studied and discussed. To the best of our knowledge, this is the first report on template-free fabrication of $\mathrm{BiVO}_{4}$ hollow spheres. This work will provide new insights and understanding on the control of morphology and enhancement of photocatalytic activity of $\mathrm{BiVO}_{4}$ and should be of significant interest in pigment, catalysis, separation technology, biomedical engineering, and nanotechnology.

\section{Experimental}

2.1. Preparation of Sample. All chemicals used in this study were of analytical grade and were used without further purification. Deionized water was used in all experiments. $1.4 \mathrm{~g}$ of $\mathrm{NH}_{4} \mathrm{VO}_{3}, 5.8 \mathrm{~g}$ of $\mathrm{Bi}\left(\mathrm{NO}_{3}\right)_{3} \cdot 5 \mathrm{H}_{2} \mathrm{O}$ and a certain amount of urea were dissolved in $50 \mathrm{~mL}$ of nitric acid aqueous solution $(2.0 \mathrm{M})$. The amount of the added urea was changed from $0,3,6$, to $9 \mathrm{~g}$, and the obtained $\mathrm{BiVO}_{4}$ powders were labeled as samples A, B, C, and D, respectively. After being stirred for $30 \mathrm{~min}$, the mixed solution was transferred into a $100-\mathrm{mL}$ teflon-lined stainless steel autoclave and kept at $180^{\circ} \mathrm{C}$ for $24 \mathrm{~h}$. The hydrothermal products were collected, washed with deionized water and anhydrous alcohol for three times, and then dried at $80^{\circ} \mathrm{C}$ for $12 \mathrm{~h}$.

2.2. Characterization. Morphological observations were performed by an S-4800 field emission scanning electron microscope (FESEM, Hitachi, Japan) and linked with an Oxford Instruments X-ray analysis system. X-ray diffraction (XRD) patterns obtained on a D/MAX-RB X-ray diffractometer (Rigaku, Japan) using $\mathrm{Cu} \mathrm{K} \alpha$ radiation at a scan rate $(2 \theta)$ of $0.05^{\circ} \mathrm{s}^{-1}$ were used to determine the identity of any phase present and their crystallite size. The accelerating voltage and applied current were $40 \mathrm{kV}$ and $80 \mathrm{~mA}$, respectively. The average crystallite size of $\mathrm{BiVO}_{4}$ was quantitatively calculated using Scherrer formula $(d=0.9 \lambda / B \cos \theta$, where $d, \lambda, B$, and $\theta$ are crystallite size, $\mathrm{Cu} \mathrm{K} \alpha$ wavelength $(0.15418 \mathrm{~nm})$, full width at half maximum intensity (FWHM) of (121) for $\mathrm{BiVO}_{4}$ peak in radians and Bragg's diffraction angle, resp.) after correcting the instrumental broadening. The Brunauer-Emmett-Teller (BET) specific surface area $\left(S_{\mathrm{BET}}\right)$ of the powders was analyzed by nitrogen adsorption in a Micromeritics ASAP 2020 nitrogen adsorption apparatus (USA). All the samples were degassed at $180^{\circ} \mathrm{C}$ prior to nitrogen adsorption measurements. The BET surface area was determined by a multipoint BET method using the adsorption data in the relative pressure $\left(P / P_{0}\right)$ range of $0.05 \sim 0.3$. Infrared (IR) spectra on pellets of the samples mixed with $\mathrm{KBr}$ were recorded on a IRAffinity-1 FTIR spectrometer (Shimadzu, Japan) at a resolution of $4 \mathrm{~cm}^{-1}$. The concentration of the samples was kept at about $0.25-$ $0.3 \%$. UV-vis diffused reflectance spectra of $\mathrm{BiVO}_{4}$ powders were obtained for the dry-pressed disk samples using a UVvis spectrometer (UV2550, Shimadzu, Japan). $\mathrm{BaSO}_{4}$ was used as a reflectance standard in a UV-vis diffuse reflectance experiment.

2.3. Measurement of Photocatalytic Activity. The photocatalytic activity of the $\mathrm{BiVO}_{4}$ samples was characterized by the photocatalytic decolorization of methylene blue (MB) aqueous solution at ambient temperature. Experimental details were as follows: $0.1 \mathrm{~g}$ of the prepared $\mathrm{BiVO}_{4}$ powder was dispersed in a $20 \mathrm{~mL} \mathrm{MB}$ aqueous solution with a concentration of $3 \times 10^{-5} \mathrm{M}$ in a $9.0 \mathrm{~cm}$ culture dish. The solution was allowed to reach an adsorption-desorption equilibrium among the photocatalyst, $\mathrm{MB}$, and water before visible-light irradiation. A $350 \mathrm{~W}$ xenon lamp with a $420 \mathrm{~nm}$ cutoff filter positioned $25 \mathrm{~cm}$ above the dish was used as a visible-light source to trigger the photocatalytic reaction. The integrated visible-light intensity striking on the surface of the reaction solution measured with a visible-light radiometer (model: FZ-A, China) was $95 \mathrm{~mW} / \mathrm{cm}^{2}$ with the wavelength range of $420-1000 \mathrm{~nm}$. The concentration of $\mathrm{MB}$ was determined by a UV-visible spectrophotometer (UV-2550, Shimadzu, Japan). After visible-light irradiation for every $30 \mathrm{~min}$, the reaction solution was filtrated to measure the concentration change of $\mathrm{MB}$.

2.4. Analysis of Hydroxyl Radicals. The formation of hydroxyl radicals $(\cdot \mathrm{OH})$ on the surface of $\mathrm{BiVO}_{4}$ under visible-light irradiation was detected by PL method using terephthalic acid as a probe molecule. Terephthalic acid readily reacts with $\cdot \mathrm{OH}$ to produce a highly fluorescent product, 2hydroxyterephthalic acid $[40,41]$. This technique has been used in radiation chemistry, sonochemistry, and biochemistry for the detection of ${ }^{\circ} \mathrm{OH}$ generated in water. The method relies on the PL signal at $425 \mathrm{~nm}$ arising from the hydroxylation of terephthalic acid with ${ }^{\circ} \mathrm{OH}$ generated at the water/catalyst interface. The PL intensity of 2hydroxyterephthalic acid is proportional to the amount of 
TABLE 1: Experimental conditions for preparation of the samples and their physical properties.

\begin{tabular}{lcccccc}
\hline No. & Urea content & Phase $^{\mathrm{a}}$ & Bandgap $(\mathrm{eV})$ & Crystalline size $(\mathrm{nm})$ & S $_{\text {BET }}\left(\mathrm{m}^{2} / \mathrm{g}\right)$ & Relative crystallinity $^{\mathrm{b}}$ \\
\hline A & 0 & $\mathrm{M}$ & 2.24 & 31.1 & 2.85 & 1.64 \\
B & 3 & $\mathrm{M}$ & 2.22 & 45.2 & 1.00 & 1.48 \\
C & 6 & $\mathrm{M}$ & 2.21 & 50.6 & 1.20 & 1.80 \\
D & 9 & $\mathrm{M}$ & 2.20 & 62.5 & 1.05 & 2.13 \\
\hline
\end{tabular}

${ }^{\mathrm{a}} \mathrm{M}$ denote monoclinic.

${ }^{b}$ Relative monoclinic crystallinity: the relative intensity of the diffraction peak from the monoclinic $(121)$ plane $($ reference $=$ the sample A prepared in pure water).

- $\mathrm{OH}$ radicals produced in water $[40,41]$. The method is rapid, sensitive, and specific and needs only a simple standard PL instrumentation. Experimental procedures were similar to the measurement of photocatalytic activity except that the MB aqueous solution was replaced by the $5 \times$ $10^{-4} \mathrm{M}$ terephthalic acid aqueous solution with a concentration of $2 \times 10^{-3} \mathrm{M} \mathrm{NaOH}$. PL spectra of generated 2hydroxyterephthalic acid were measured on an Hitachi F7000 fluorescence spectrophotometer. After UV irradiation for every $30 \mathrm{~min}$, the reaction solution was filtrated to measure the increase of the PL intensity at $425 \mathrm{~nm}$ excited by $315 \mathrm{~nm}$ light [15].

\section{Results and Discussion}

3.1. XRD Study. XRD was used to investigate the effects of the amount of urea on phase structure and crystallite size of the prepared samples. Figure 1 shows the XRD patterns of $\mathrm{BiVO}_{4}$ samples obtained with different amount of urea. It is clear that all the $\mathrm{BiVO}_{4}$ samples have a monoclinic scheelite structure (JCPDS Card no. 14-0688). No diffraction peaks of any other phases or impurities are detected, and the narrow line widths indicate a high degree of crystallinity. It is reasonable to infer that hydrothermal treatment at $180^{\circ} \mathrm{C}$ for $24 \mathrm{~h}$ is sufficient for the preparation of pure monoclinic scheelite $\mathrm{BiVO}_{4}$, which is consistent with the previous reports $[39,42]$. Usually, monoclinic scheelite $\mathrm{BiVO}_{4}$ is usually obtained by the high-temperature process, while tetragonal $\mathrm{BiVO}_{4}$ (zircon structure) is prepared in aqueous media by the low-temperature process. The phase transition from tetragonal $\mathrm{BiVO}_{4}$ (zircon structure) to monoclinic $\mathrm{BiVO}_{4}$ (scheelite structure) irreversibly occurs at 670-770 K [28]. Thus, it can be concluded that the phase transition from tetragonal $\mathrm{BiVO}_{4}$ to monoclinic $\mathrm{BiVO}_{4}$ is thermodynamically favored, and hydrothermal environment promotes this phase transformation due to a nonequilibrium pressure environment in hydrothermal treatment [43]. Moreover, monoclinic $\mathrm{BiVO}_{4}$ is a thermodynamically more stable phase while tetragonal $\mathrm{BiVO}_{4}$ is a kinetically one $[29,36]$. In this reaction system, the tetragonal $\mathrm{BiVO}_{4}$ is a metastable phase and can be easily transformed to the monoclinic scheelite $\mathrm{BiVO}_{4}$ with an increase in hydrothermal time (24h) [44].

Further observation shows that with increasing the amount of urea, XRD peak intensities of monoclinic $\mathrm{BiVO}_{4}$ become steadily stronger, and the width of XRD diffraction peaks of monoclinic $\mathrm{BiVO}_{4}$ become slightly narrower, indicating that the enhancement of crystallization and formation

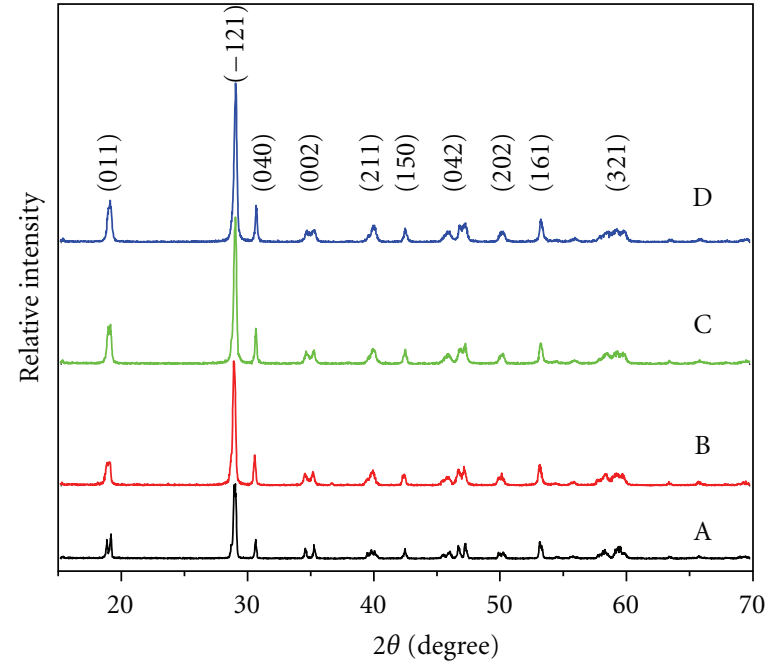

FIGURE 1: XRD patterns of $\mathrm{BiVO}_{4}$ samples prepared with different amount of urea ranging from 0 (A), 3 (B), 6 (C) to $9 \mathrm{~g}(\mathrm{D})$ at $180^{\circ} \mathrm{C}$ for $24 \mathrm{~h}$.

of greater $\mathrm{BiVO}_{4}$ crystallites. The average crystalline sizes change from $31.1,45.2,50.6$ to $62.5 \mathrm{~nm}$ (see Table 1 ). This result is in good agreement with the previous report that urea added in the reaction system enhanced the crystallization of monoclinic phase and promoted the growth of crystallites [43]. The formation of greater $\mathrm{BiVO}_{4}$ crystallites may be related to the fact that urea coordinates to bismuth ions to form complex, the dissociation of the complex in situ generates $\mathrm{Bi}^{3+}$, the combination of $\mathrm{VO}_{3}{ }^{-}$and the released $\mathrm{Bi}^{3+}$ results in the formation of the greater $\mathrm{BiVO}_{4}$ crystallites [45]. The coordinating strength of complexes formed under different conditions would affect the release speed and the monomer concentration of free $\mathrm{Bi}^{3+}$ in the solution. Generally, the aggregation behavior is strongly correlated to the nucleation rate of the primary nanoparticles, which can be adjusted by controlling the reaction rate [46]. The stronger coordination led to lowering free $\mathrm{Bi}^{3+}$ concentration in the solution, which prevented the plosive production of $\mathrm{BiVO}_{4}$ and suppressed the nucleation. As a result, their progressive crystal growth is favored, rather than aggregation. In this case, the more urea added, the lower concentration of free $\mathrm{Bi}^{3+}$, which slow nucleation rate and then increase the crystal growth. Therefore, it is not surprising that with increasing the amount of urea, the products consist of greater $\mathrm{BiVO}_{4}$ crystallites. 
3.2. UV-Vis and FTIR Spectra. Figure 2 shows the UV-visible diffuse reflectance spectra of samples $A$ and D. The two samples exhibit a strong absorption in the UV-visible light region, and sample $\mathrm{D}$ with hollow structure shows the enhanced visible-light absorption. The steep shape of the spectra indicates that the visible-light absorption was not due to the transition from impurity levels but to the bandgap transition. The absorption edge for sample A is at ca. $550 \mathrm{~nm}$, which is consistent with the characteristic absorption of monoclinic $\mathrm{BiVO}_{4}$ [28]. For monoclinic scheelite $\mathrm{BiVO}_{4}$, the valence band (VB) is formed by a hybridization of the $\mathrm{Bi}_{6 \mathrm{~s}}$ and $\mathrm{O}_{2 p}$ orbital, whereas the conduction band is composed of $\mathrm{V}_{3 \mathrm{~d}}$ orbital [43]. The presence of $\mathrm{Bi}_{6 \mathrm{~s}}$ in the top of the valence bands results in a more negative energy level of the valence band and then a decrease in the band gap [47]. It is apparent that the diffuse reflectance spectra of $\mathrm{BiVO}_{4}$ hollow microspheres exhibit a red shift and increased absorption in the visible-light range, which is ascribed to the unique hollow configuration of sample D. Hollow structure allows multiple scattering of UV-vis light within their frameworks, leading to a longer optical path length for light transport and a greater absorbance than those for large irregular aggregates sample. It also leads to the enhanced photocatalytic activity of $\mathrm{BiVO}_{4}$ hollow structure. Similar results were also reported by Zhou et al. [36]. The bandgap of a semiconductor can be estimated from a plot of $(\alpha h \nu)^{2}$ versus photon energy $(h \nu)$ [48-50]. The estimated $E_{g}$ of sample $\mathrm{A}$ and $\mathrm{D}$ from the intercept of the tangents to the plots were $2.24 \mathrm{eV}$ and $2.20 \mathrm{eV}$, respectively. In addition, the conduction band (CB) edge of a semiconductor at the point of zero charge $\left(\mathrm{pH}_{\mathrm{zpc}}\right)$ can be predicted by (1):

$$
E_{\mathrm{CB}}{ }^{0}=X-E^{\mathrm{c}}-\frac{1}{2} E_{g},
$$

where $X$ is the absolute electronegativity of the semiconductor, expressed as the geometric mean of the absolute electronegativity of the constituent atoms, which is defined as the arithmetic mean of the atomic electron affinity and the first ionization energy; $E^{c}$ is the energy of free electrons on the hydrogen scale (ca. $4.5 \mathrm{eV}) ; E_{g}$ is the band gap of the semiconductor [21]. For $\mathrm{BiVO}_{4}$, the value of $X$ is 6.035 . According to the values of $E_{g}$ estimated above and the foregoing formula, the calculated $E_{\mathbf{C B}}$ and $E_{\mathrm{VB}}$ of sample $A$ were $0.415 \mathrm{eV}$ and $2.655 \mathrm{eV}$, respectively. For sample D, $E_{\mathrm{CB}}$ and $E_{\mathrm{VB}}$ were $0.435 \mathrm{eV}$ and $2.635 \mathrm{eV}$, respectively. These data clearly demonstrate that the electronic structures of $\mathrm{BiVO}_{4}$ were slightly changed due to the varying $\mathrm{pH}$ caused by the decomposition of urea [43].

3.3. SEM Images. The morphologies of the samples were observed by SEM. Figure 3 shows the SEM images of the powder samples prepared with different amount of urea. It is clearly seen that the amount of urea has a significant influence on the morphologies of samples. As shown in Figure 3(a), the products are composed of large aggregates with ill-defined shape and inhomogeneous size in the absence of urea. With the addition of urea, hollow structures appear in the products. When $3 \mathrm{~g}$ urea is added in this

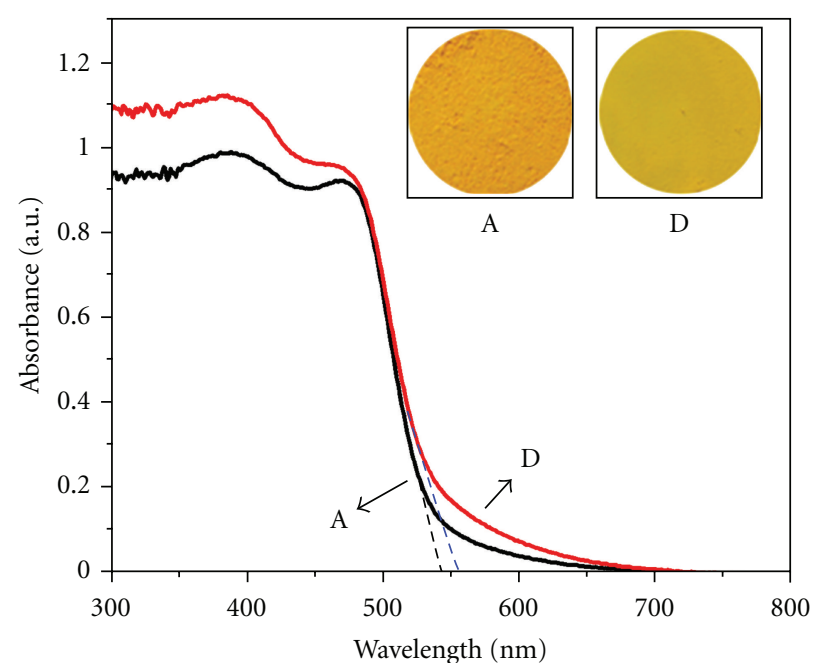

FIGURE 2: UV-visible absorption spectra and corresponding colors (inset) of sample A and D.

reaction system, the as-synthesized products are hollow microspheres with the diameter of about $3 \mu \mathrm{m}$, coexisting with solid microspheres (Figure 3(b)). Figure 3(c) clearly illustrates that most of the microspheres appear hollow structures with the wall thinness of $0.8-1.0 \mu \mathrm{m}$ when the amount of urea increases to $6 \mathrm{~g}$. As the amount of urea further increases to $9 \mathrm{~g}$, SEM image (Figure $3(\mathrm{~d})$ ) indicates that the rough external shells of the hollow microspheres consist of loosely packed nanoparticles and progressively thinned. The above results indicate that hollow microspheres could not form without the addition of urea, contrarily, $\mathrm{BiVO}_{4}$ hollow microspheres are easily produced in the presence of urea, and the hollowing rate is strongly related to the amount of urea added. With increasing the amount of urea, the hollowing rate increases. Urea enhances the dissolution of the interior and mass transfer from interior of the spheres to outer surface during reactive process, accompanied by an enhancement of crystallization of monoclinic $\mathrm{BiVO}_{4}$ [19].

To investigate the formation mechanism of $\mathrm{BiVO}_{4}$ hollow microspheres, a detailed time-dependent evolution experiment was carried out. Figure 4 shows the XRD patterns of the samples obtained with $9 \mathrm{~g}$ urea at $180^{\circ} \mathrm{C}$ for varying hydrothermal time. It can be seen that tetragonal $\mathrm{BiVO}_{4}$ is formed after hydrothermal reaction for $1 \mathrm{~h}$, along with monoclinic $\mathrm{BiVO}_{4}$, but tetragonal $\mathrm{BiVO}_{4}$ is completely transformed into monoclinic as the time is prolonged to $24 \mathrm{~h}$. The corresponding SEM images (Figure 5(a)) show that the solid microspheres with the diameter of about $2.7 \mu \mathrm{m}$ are obtained by self-assembly of precursor nanoparticles after $1 \mathrm{~h}$ reaction. After a reaction time of $6 \mathrm{~h}$, hollow microspheres can be observed in the products (Figure 5(b)). When the hydrothermal time prolongs to $12 \mathrm{~h}$, the shell of the hollow microspheres becomes thinner (Figure 5(c)). The thickness of the shell wall changes from $1.3 \mu \mathrm{m}$ at $6 \mathrm{~h}, 1 \mu \mathrm{m}$ at $12 \mathrm{~h}$ to $0.6 \mu \mathrm{m}$ at $24 \mathrm{~h}$. Therefore, it can be inferred from the above results that the thickness of shell walls of $\mathrm{BiVO}_{4}$ hollow spheres could be easily controlled by changing hydrothermal time. The longer the reaction time, 


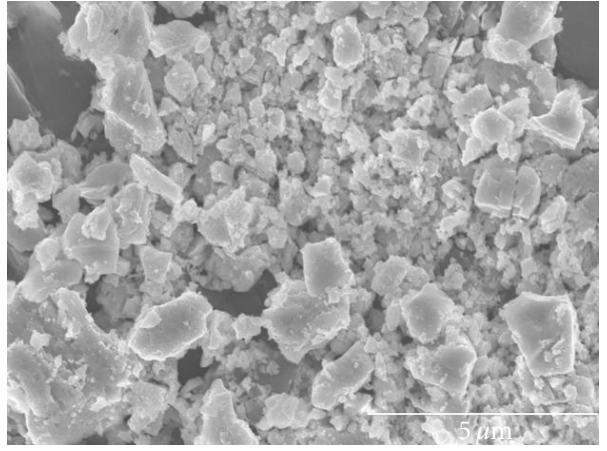

(a)

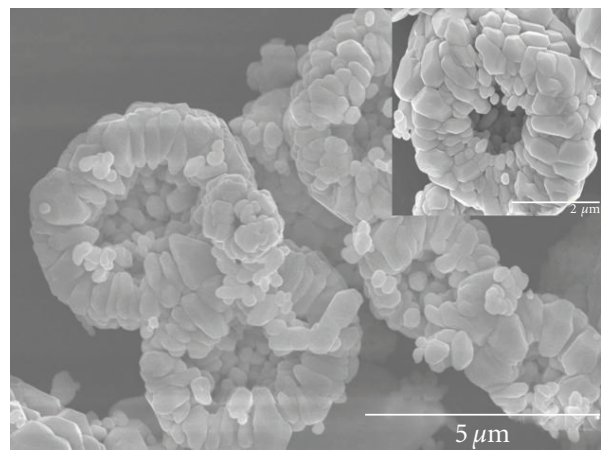

(c)

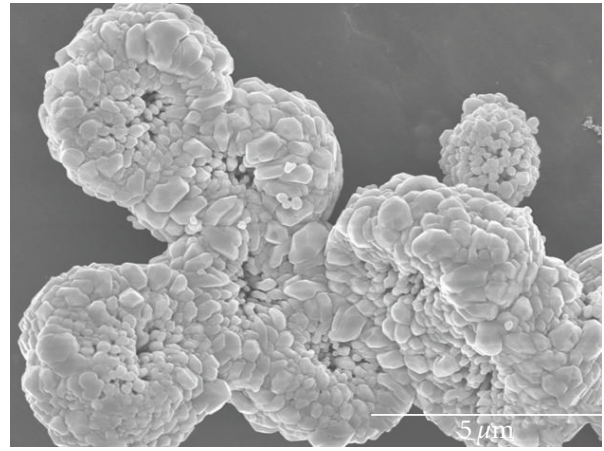

(b)

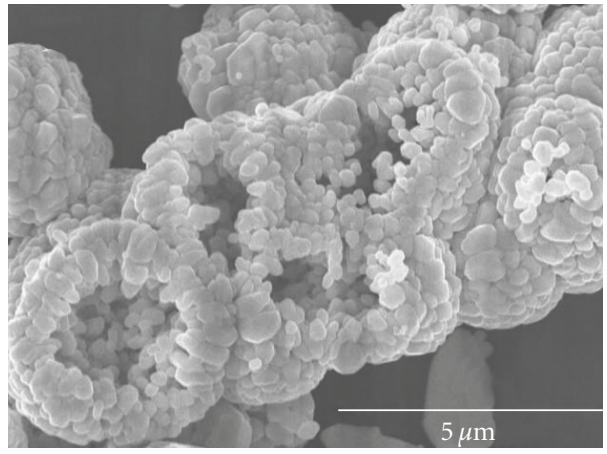

(d)

Figure 3: SEM images of $\mathrm{BiVO}_{4}$ samples prepared with different amount of urea ranging from 0 (a), 3 (b), 6 (c) to $9 \mathrm{~g} \mathrm{(d)} \mathrm{at} 180^{\circ} \mathrm{C}$ for $24 \mathrm{~h}$.

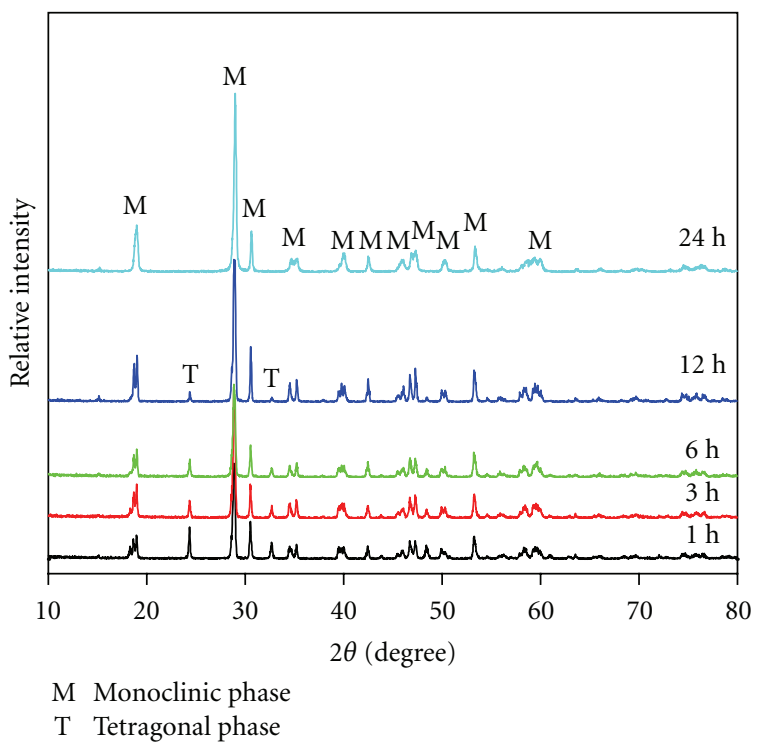

FIGURE 4: XRD patterns of $\mathrm{BiVO}_{4}$ samples prepared with $9 \mathrm{~g}$ urea at different reaction time from $1,3,6,12$ to $24 \mathrm{~h}$.

the thinner the shell walls of hollow spheres. Based on these above results, a localized Ostwald ripening or chemically induced self-transformation mechanism can be used to explain the formation of $\mathrm{BiVO}_{4}$ hollow spheres. The mechanism for this template-free formation of hollow spheres has been elaborated in our previous works $[19,51-54]$.
The formation of monoclinic-phase $\mathrm{BiVO}_{4}$ hollow spheres comes from the dissolution and recrystallization of tetragonal $\mathrm{BiVO}_{4}$ phase as others report $[36,43,55]$. This selftransformation is sustained by the higher solubility of the as-formed metastable tetragonal $\mathrm{BiVO}_{4}$ spheres core, which resulted in an increase in the local supersaturation such that secondary nucleation and growth of crystalline monoclinic $\mathrm{BiVO}_{4}$ occurred specially on the external surface of the spheres [17].

3.4. Photocatalytic Activity. The photocatalytic activity of the prepared samples was evaluated by photocatalytic degradation decolorization of $\mathrm{MB}$ aqueous solution under visiblelight $(\lambda>420 \mathrm{~nm})$ illumination. Figure 6 displays the changes in the absorption spectra of an $\mathrm{MB}$ aqueous solution exposed to visible light for various time in the presence of sample D. Methylene blue (MB) shows a maximum absorption band at $664 \mathrm{~nm}$. Under visible-light illumination, an apparent decrease of $\mathrm{MB}$ absorption at $664 \mathrm{~nm}$ was observed. This indicates that the degradation rate of $\mathrm{MB}$ was very fast at the beginning of irradiation and then became slow. The color of the dispersion disappeared after $180 \mathrm{~min}$ of irradiation, demonstrating that the chromophoric structure of the dye was destroyed. A sharp decrease of the major absorption band within $3 \mathrm{~h}$ indicates that sample D exhibits excellent photocatalytic activity in the degradation of MB.

Figure 7 shows the comparison of photocatalytic activities of the samples prepared with different amount of urea. It is demonstrated that the self-degradation of MB is extremely 


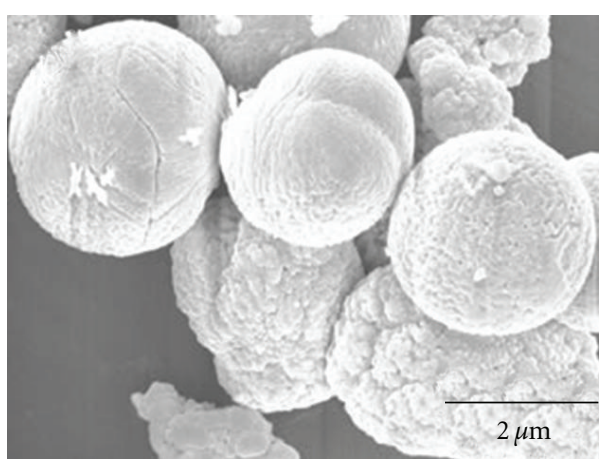

(a)

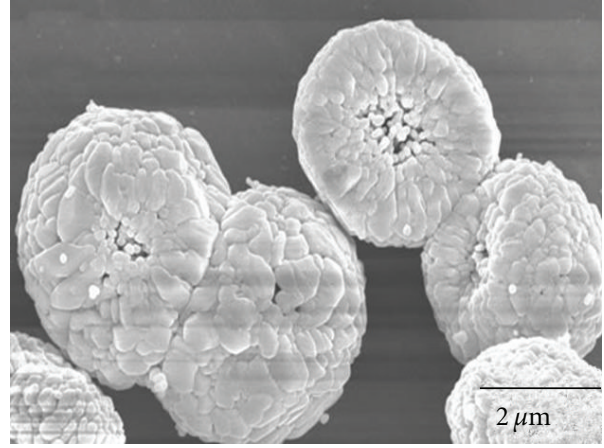

(b)

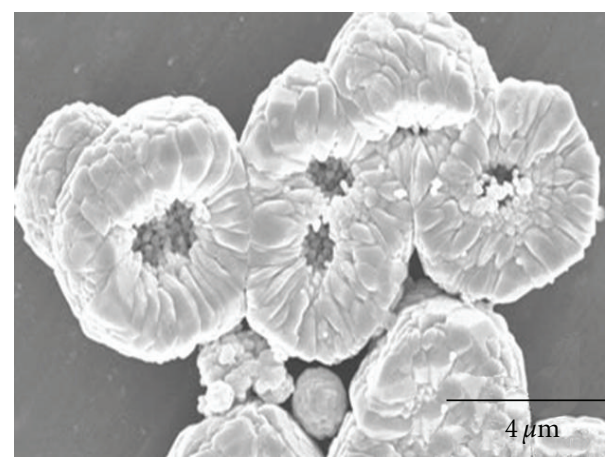

(c)

Figure 5: SEM images of $\mathrm{BiVO}_{4}$ samples prepared with $9 \mathrm{~g}$ urea at different reaction time from 1 (a), 6 (b), to $12 \mathrm{~h}$ (c).

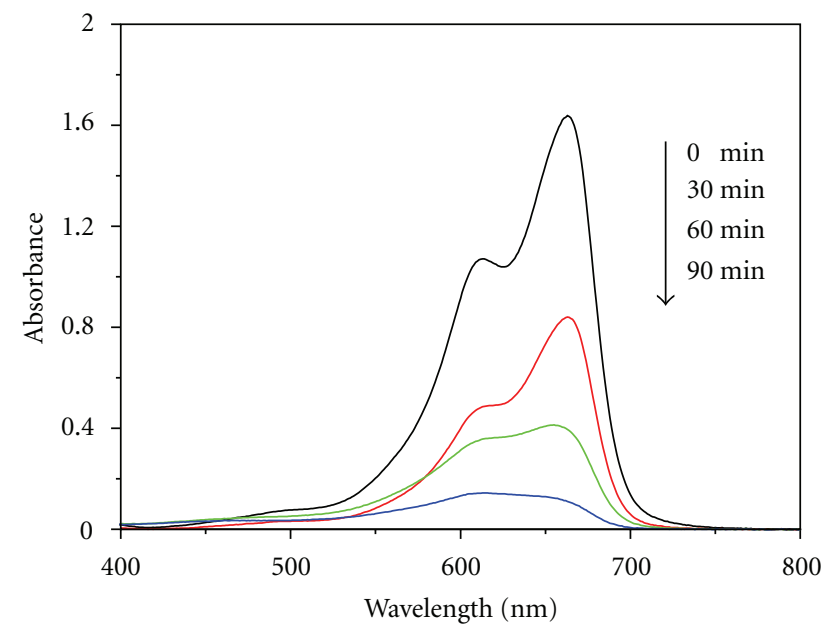

Figure 6: Absorption changes of $\mathrm{MB}$ aqueous solution at room temperature in the presence of the sample D under visible-light irradiation.

slow; only $6 \%$ of $\mathrm{MB}$ is photolyzed after 180 min irradiation (Figure 7). When $\mathrm{BiVO}_{4}$ samples as photocatalysts are added in the MB solution, the degradation rate of $\mathrm{MB}$ significantly increases. Moreover, it is clearly seen that the degradation rate of the samples obtained in the presence of urea is higher than that of the samples prepared without urea. Urea added in the reaction system has a positive influence on the photocatalytic activity of the $\mathrm{BiVO}_{4}$ samples. This is due

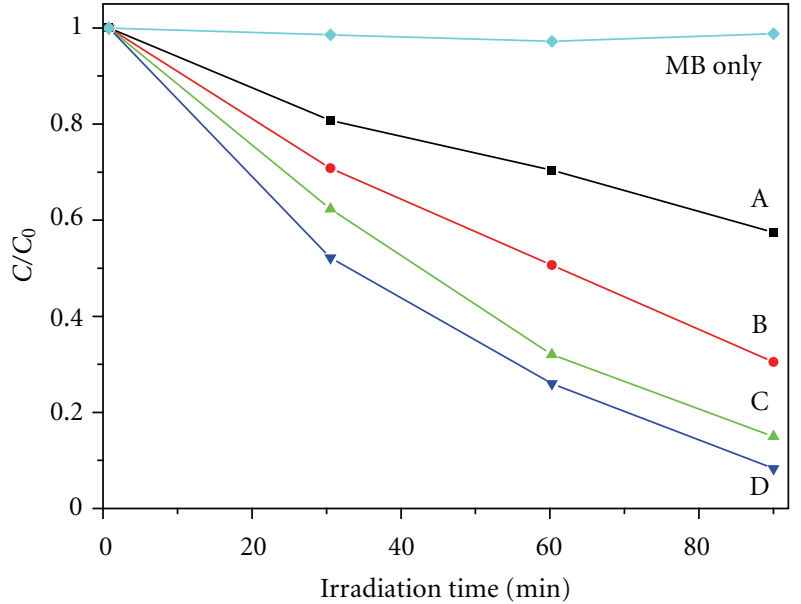

Figure 7: Comparison of photocatalytic activities of samples A, $\mathrm{B}, \mathrm{C}$, and $\mathrm{D}$ for the photocatalytic decolorization of $\mathrm{MB}$ aqueous solution at ambient temperature; $C$ and $C_{0}$ denote the reaction and initial concentration of $\mathrm{MB}$ in the system, respectively.

to the following two factors. First, hollow inner structures allow light scattering inside their hollow interior, which enhances light harvesting and thus increases the quantities of photogenerated electrons and holes available to participate in the photocatalytic decomposition reactions of the contaminants $[15,48]$. Second, specific surface area and crystallinity are two conflicting factors influencing the photocatalytic activity of photocatalyst. A large surface area is usually 


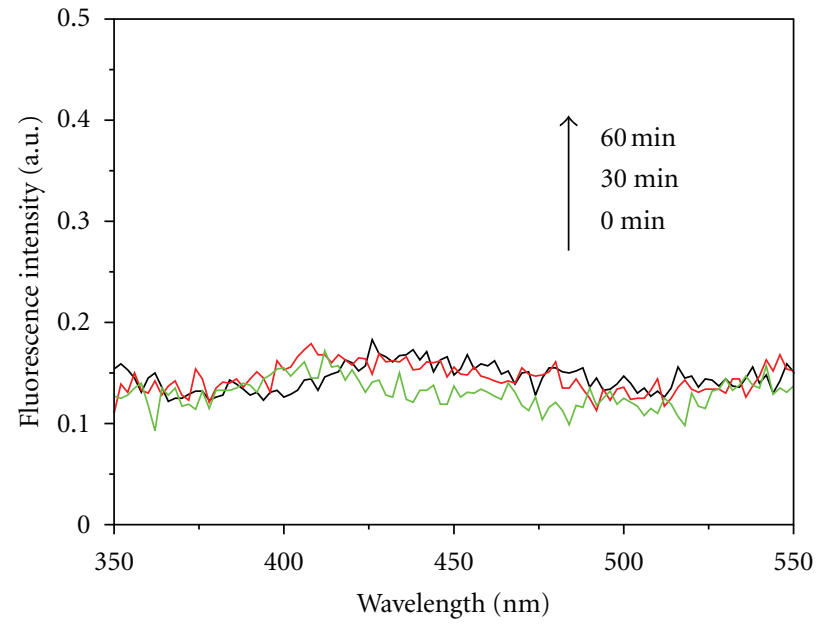

(a)

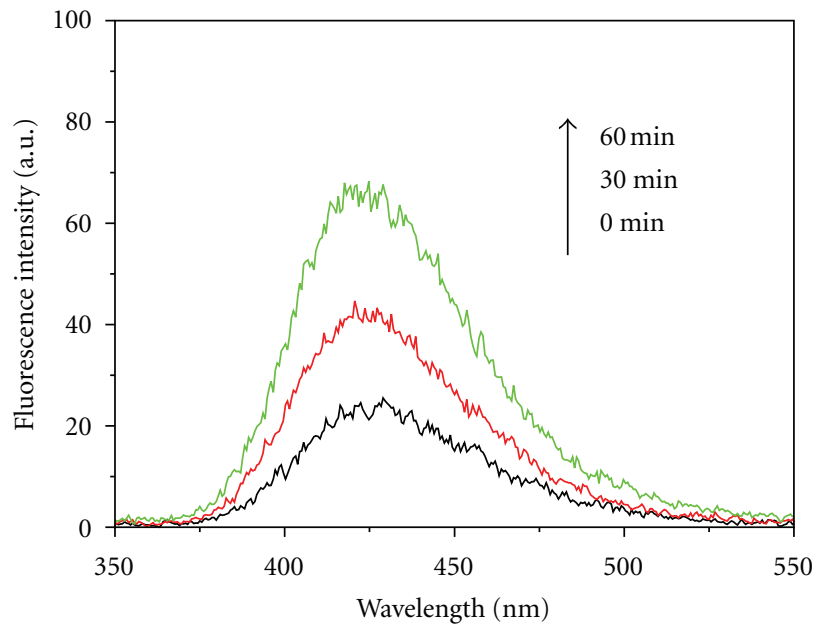

(b)

FIGURE 8: PL spectral changes observed during illumination of (a) as-prepared $\mathrm{BiVO}_{4}$ and (b) $\mathrm{TiO}_{2}$ sample in a $5 \times 10^{-4} \mathrm{M}$ basic solution of terephthalic acid (excitation at $315 \mathrm{~nm}$ ). Each fluorescence spectrum was recorded every $30 \mathrm{~min}$ of visible light illumination.

associated with a large amount of crystalline defects or weak crystallization, which favor the recombination of photogenerated electrons and holes, causing a poor photoactivity. Therefore, amorphous $\mathrm{TiO}_{2}$ powders usually show a large specific surface area, but a poor or negligible photocatalytic activity due to recombination of photoexcited electrons and positive holes at defects (i.e., imperfections, impurities, dangling bonds, or microvoids) located on the surface and in the bulk of particles $[56,57]$. This indicates that crystallinity is another important requirement for high photocatalytic activity. Hence, it is easy to understand that with increasing the amount of urea, the crystallinity increases, resulting in the enhancement of photocatalytic activity.

Our experiments also indicate that $\mathrm{BiVO}_{4}$ hollow spheres are more readily separated from the slurry system by filtration or sedimentation after photocatalytic reaction and reused than conventional nanosized powder photocatalytic materials due to their large weight, weak Brownian motion, and good mobility [15]. After five recycles for the photodegradation of $\mathrm{MB}$, the catalyst did not exhibit any significant loss of activity, confirming that $\mathrm{BiVO}_{4}$ hollow spheres were not deactivated during the photocatalytic oxidation of the pollutant molecules. Further investigation indicates that other colorless organic pollutants such as phenol are also quickly decomposed by the prepared $\mathrm{BiVO}_{4}$ hollow spheres under visible-light irradiation. To the best of our knowledge, this is the first time to report template-free preparation and enhanced photocatalytic activity of $\mathrm{BiVO}_{4}$ hollow spheres. We believe that the prepared $\mathrm{BiVO}_{4}$ hollow spheres are also of great interest in pigment, catalysis, separation technology, biomedical engineering, and nanotechnology.

3.5. Hydroxyl Radical Analysis. To understand the involved active species in the photocatalytic process of $\mathrm{BiVO}_{4}$, the formation of hydroxyl radicals $\left({ }^{\bullet} \mathrm{OH}\right)$ on the surface of visible light illuminated $\mathrm{BiVO}_{4}$ is detected by the PL technique using terephthalic acid as a probe molecule. For comparison, the $\mathrm{TiO}_{2}$ system was also observed under the same conditions. Figure 8 shows PL spectral changes observed during visiblelight illumination of as-prepared $\mathrm{BiVO}_{4}$ and $\mathrm{TiO}_{2}$ powders in a $5 \times 10^{-4} \mathrm{M}$ basic solution of terephthalic acid (excitation at $315 \mathrm{~nm}$ ). There is no PL observed when the $\mathrm{BiVO}_{4}$ suspension is irradiated, indicating that no ${ }^{\circ} \mathrm{OH}$ radical is produced. However, in the case of $\mathrm{TiO}_{2}$, a gradual increase in PL intensity at about $425 \mathrm{~nm}$ is observed with increasing irradiation time, indicating the production of the $\cdot \mathrm{OH}$ radicals. The above results show that the ${ }^{\bullet} \mathrm{OH}$ radicals are not the main active oxygen species in the photochemical process of $\mathrm{MB} / \mathrm{BiVO}_{4}$ system. This can be explained according to the location of the valence bandedges $\left(E_{\mathrm{VB}}\right)$ of $\mathrm{BiVO}_{4}$ and the normal potential of $\mathrm{OH}^{-} / \cdot \mathrm{OH}$ couples, their potentials are 2.635 and $2.7 \mathrm{~V}$ versus SCE, respectively, suggesting that the holes photogenerated on the surface of $\mathrm{BiVO}_{4}$ could not react with $\mathrm{OH}^{-} / \mathrm{H}_{2} \mathrm{O}$ to form $\cdot \mathrm{OH}$. Consequently, it is not surprising that no hydroxyl radicals are observed on the surface of visible light illuminated $\mathrm{BiVO}_{4}$. The interfacial energy scheme at the $\mathrm{BiVO}_{4} /$ electrolyte interface is summarized in Figure 9. Therefore, we have reason to think that the photocatalytic degradation of $\mathrm{MB}$ in the presence of $\mathrm{BiVO}_{4}$ is due to the direct participation of the photogenerated holes [15].

\section{Conclusion}

Monoclinic $\mathrm{BiVO}_{4}$ hollow microspheres with diameters of about $2-4 \mu \mathrm{m}$ are successfully fabricated on a large scale by a simple hydrothermal method without using any templates. Localized Ostwald ripening and chemically induced selftransformation mechanism are thought to be the main driving force for the formation of hollow spheres. Urea plays a key role in the formation of $\mathrm{BiVO}_{4}$ hollow microspheres. The average crystallite size, specific surface areas, hollow 


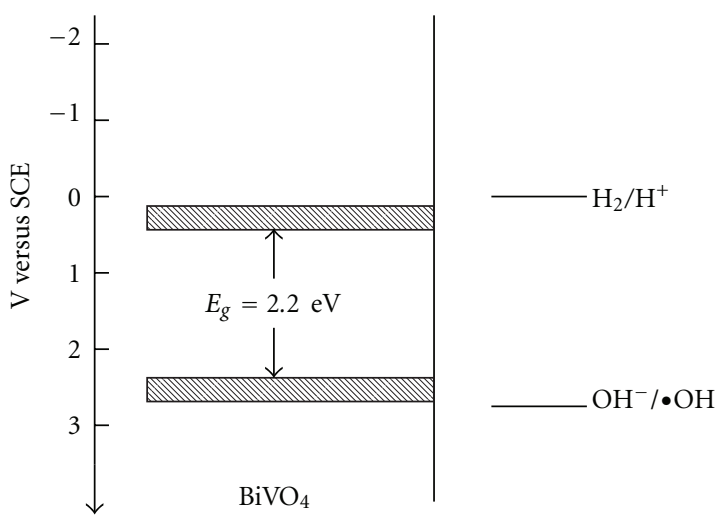

FIGURE 9: Energy scheme at the $\mathrm{BiVO}_{4} /$ electrolyte interface.

interior structures, and photocatalytic activity of $\mathrm{BiVO}_{4}$ hollow spheres could be tuned by changing the amount of urea. With increasing the amount of urea, the crystallites grow to larger size, the core hollowing takes place faster, and photocatalytic activity increases. The direct hole transfer (instead of $\cdot \mathrm{OH}$ radicals) plays an important role in the degradation of MB.

\section{Acknowledgments}

This work was partially supported by the National Natural Science Foundation of China (51072154 and 51102190), Natural Science Foundation of Hubei Province (2010CDA078), National Basic Research Program of China (2009CB939704), and Self-determined and Innovative Research Funds of SKLWUT.

\section{References}

[1] L. P. Zhu, H. M. Xiao, W. D. Zhang, G. Yang, and S. Y. Fu, "One-pot template-free synthesis of monodisperse and singlecrystal magnetite hollow spheres by a simple solvothermal route," Crystal Growth and Design, vol. 8, no. 3, pp. 957-963, 2008.

[2] Y. Zheng, Y. Cheng, Y. Wang, L. Zhou, F. Bao, and C. Jia, "Metastable $\gamma$-MnS hierarchical architectures: synthesis, characterization, and growth mechanism," Journal of Physical Chemistry B, vol. 110, no. 16, pp. 8284-8288, 2006.

[3] J. Yu, W. Liu, and H. Yu, "A one-pot approach to hierarchically nanoporous titania hollow microspheres with high photocatalytic activity," Crystal Growth and Design, vol. 8, no. 3, pp. 930-934, 2008.

[4] J. Yu, H. Yu, H. Guo, M. Li, and S. Mann, "Spontaneous formation of a tungsten trioxide sphere-in-shell superstructure by chemically induced self-transformation," Small, vol. 4, no. 1, pp. 87-91, 2008.

[5] J. Yu and L. Shi, "One-pot hydrothermal synthesis and enhanced photocatalytic activity of trifluoroacetic acid modified $\mathrm{TiO}_{2}$ hollow microspheres," Journal of Molecular Catalysis A, vol. 326, no. 1-2, pp. 8-14, 2010.

[6] F. Caruso, R. A. Caruso, and H. Möhwald, "Nanoengineering of inorganic and hybrid hollow spheres by colloidal templating," Science, vol. 282, no. 5391, pp. 1111-1114, 1998.
[7] J. Yu and X. Yu, "Hydrothermal synthesis and photocatalytic activity of zinc oxide hollow spheres," Environmental Science and Technology, vol. 42, no. 13, pp. 4902-4907, 2008.

[8] S. W. Kim, M. Kim, W. Y. Lee, and T. Hyeon, "Fabrication of hollow palladium spheres and their successful application to the recyclable heterogeneous catalyst for suzuki coupling reactions," Journal of the American Chemical Society, vol. 124, no. 26, pp. 7642-7643, 2002.

[9] J. Gao, B. Zhang, X. Zhang, and B. Xu, "Magneticdipolar-interaction-induced self-assembly affords wires of hollow nanocrystals of cobalt selenide," Angewandte ChemieInternational Edition, vol. 45, no. 8, pp. 1220-1223, 2006.

[10] A. D. Dinsmore, M. F. Hsu, M. G. Nikolaides, M. Marquez, A. R. Bausch, and D. A. Weitz, "Colloidosomes: selectively permeable capsules composed of colloidal particles," Science, vol. 298, no. 5595, pp. 1006-1009, 2002.

[11] Y. Li, J. Shi, Z. Hua, H. Chen, M. Ruan, and D. Yan, "Hollow spheres of mesoporous aluminosilicate with a three-dimensional pore network and extraordinarily high hydrothermal stability," Nano Letters, vol. 3, no. 5, pp. 609612, 2003.

[12] J. H. Park, C. Oh, S. I. Shin, S. K. Moon, and S. G. Oh, "Preparation of hollow silica microspheres in W/O emulsions with polymers," Journal of Colloid and Interface Science, vol. 266, no. 1, pp. 107-114, 2003.

[13] M. Yang and J. J. Zhu, "Spherical hollow assembly composed of $\mathrm{Cu}_{2} \mathrm{O}$ nanoparticles," Journal of Crystal Growth, vol. 256, no. 1-2, pp. 134-138, 2003.

[14] D. H. M. Buchold and C. Feldmann, "Nanoscale $\gamma$-AIO $(\mathrm{OH})$ hollow spheres: synthesis and container-type functionality," Nano Letters, vol. 7, no. 11, pp. 3489-3492, 2007.

[15] X. Yu, J. Yu, B. Cheng, and B. Huang, "One-pot templatefree synthesis of monodisperse zinc sulfide hollow spheres and their photocatalytic properties," Chemistry-A European Journal, vol. 15, no. 27, pp. 6731-6739, 2009.

[16] H. G. Yang and H. C. Zeng, "Preparation of hollow anatase $\mathrm{TiO}_{2}$ nanospheres via Ostwald ripening," Journal of Physical Chemistry B, vol. 108, no. 11, pp. 3492-3495, 2004.

[17] Y. Yin, R. M. Rioux, C. K. Erdonmez, S. Hughes, G. A. Somorjal, and A. P. Alivisatos, "Formation of hollow nanocrystals through the nanoscale kirkendall effect," Science, vol. 304, no. 5671, pp. 711-714, 2004.

[18] H. G. Yang and H. C. Zeng, "Self-construction of hollow $\mathrm{SnO}_{2}$ octahedra based on two-dimensional aggregation of nanocrystallites," Angewandte Chemie-International Edition, vol. 43, no. 44, pp. 5930-5933, 2004.

[19] J. Yu, H. Guo, S. A. Davis, and S. Mann, "Fabrication of hollow inorganic microspheres by chemically induced selftransformation," Advanced Functional Materials, vol. 16, no. 15, pp. 2035-2041, 2006.

[20] S. Kohtani, S. Makino, A. Kudo et al., "Photocatalytic degradation of 4-n-nonylphenol under irradiation from solar simulator: comparison between $\mathrm{BiVO}_{4}$ and $\mathrm{TiO}_{2}$ photocatalysts," Chemistry Letters, no. 7, pp. 660-661, 2002.

[21] M. Long, W. Cai, J. Cai, B. Zhou, X. Chai, and Y. Wu, "Efficient photocatalytic degradation of phenol over Co3O 4/BiVO4 composite under visible light irradiation," Journal of Physical Chemistry B, vol. 110, no. 41, pp. 20211-20216, 2006.

[22] H. Q. Jiang, H. Endo, H. Natori, M. Nagai, and K. Kobayashi, "Fabrication and efficient photocatalytic degradation of methylene blue over $\mathrm{CuO} / \mathrm{BiVO}_{4}$ composite under visiblelight irradiation," Materials Research Bulletin, vol. 44, no. 3, pp. 700-706, 2009. 
[23] L. Zhang, D. Chen, and X. Jiao, "Monoclinic structured $\mathrm{BiVO}_{4}$ nanosheets: hydrothermal preparation, formation mechanism, and coloristic and photocatalytic properties," Journal of Physical Chemistry B, vol. 110, no. 6, pp. 2668-2673, 2006.

[24] L. Zhou, W. Wang, S. Liu, L. Zhang, H. Xu, and W. Zhu, "A sonochemical route to visible-light-driven high-activity $\mathrm{BiVO}_{4}$ photocatalyst," Journal of Molecular Catalysis A, vol. 252, no. 1-2, pp. 120-124, 2006.

[25] K. Sayama, A. Nomura, T. Arai et al., "Photoelectrochemical decomposition of water into $\mathrm{H}_{2}$ and $\mathrm{O}_{2}$ on porous $\mathrm{BiVO}_{4}$ thinfilm electrodes under visible light and significant effect of $\mathrm{Ag}$ Ion treatment," Journal of Physical Chemistry B, vol. 110, no. 23, pp. 11352-11360, 2006.

[26] A. Kudo, K. Ueda, H. Kato, and I. Mikami, "Photocatalytic $\mathrm{O}_{2}$ evolution under visible light irradiation on $\mathrm{BiVO}_{4}$ in aqueous $\mathrm{AgNO}_{3}$ solution," Catalysis Letters, vol. 53, no. 3-4, pp. 229230, 1998.

[27] S. Kohtani, J. Hiro, N. Yamamoto, A. Kudo, K. Tokumura, and R. Nakagaki, "Adsorptive and photocatalytic properties of Agloaded $\mathrm{BiVO}_{4}$ on the degradation of 4-n-alkylphenols under visible light irradiation," Catalysis Communications, vol. 6, no. 3, pp. 185-189, 2005.

[28] A. Kudo, K. Omori, and H. Kato, "A novel aqueous process for preparation of crystal form-controlled and highly crystalline $\mathrm{BiVO}_{4}$ powder from layered vanadates at room temperature and its photocatalytic and photophysical properties," Journal of the American Chemical Society, vol. 121, no. 49, pp. 1145911467, 1999.

[29] S. Tokunaga, H. Kato, and A. Kudo, "Selective preparation of monoclinic and tetragonal $\mathrm{BiVO}_{4}$ with scheelite structure and their photocatalytic properties," Chemistry of Materials, vol. 13, no. 12, pp. 4624-4628, 2001.

[30] P. Madhusudan, J. Ran, J. Zhang, J. Yu, and G. Liu, "Novel urea assisted hydrothermal synthesis of hierarchical $\mathrm{BiVO}_{4} / \mathrm{Bi}_{2} \mathrm{O}_{2} \mathrm{CO}_{3}$ nanocomposites with enhanced visible-light photocatalytic activity," Applied Catalysis B, vol. 110, pp. 286295, 2011.

[31] P. B. Avakyan, M. D. Nersesyan, and A. G. Merzhanov, "New materials for electronic engineering," American Ceramic Society Bulletin, vol. 75, no. 2, pp. 50-55, 1996.

[32] P. Shuk, H. D. Wiemhöfer, U. Guth, W. Göpel, and M. Greenblatt, "Oxide ion conducting solid electrolytes based on $\mathrm{Bi}_{2} \mathrm{O}_{3}$," Solid State Ionics, vol. 89, no. 3-4, pp. 179-196, 1996.

[33] K. Shantha and K. B. R. Varma, "Preparation and characterization of nanocrystalline powders of bismuth vanadate," Materials Science and Engineering B, vol. 60, no. 1, pp. 66-75, 1999.

[34] J. D. Bierlein and A. W. Sleight, "Ferroelasticity in $\mathrm{BiVO}_{4}$," Solid State Communications, vol. 16, no. 1, pp. 69-70, 1975.

[35] L. Hoffart, U. Heider, R. A. Huggins, W. Witschel, R. Jooss, and A. Lentz, "Crystal growth and conductivity investigations on $\mathrm{BiVO}_{4}$ single crystals," Ionics, vol. 2, no. 1, pp. 34-38, 1996.

[36] L. Zhou, W. Wang, L. Zhang, H. Xu, and W. Zhu, "Singlecrystalline $\mathrm{BiVO}_{4}$ microtubes with square cross-sections: microstructure, growth mechanism, and photocatalytic property," Journal of Physical Chemistry C, vol. 111, no. 37, pp. 13659-13664, 2007.

[37] W. Yin, W. Wang, M. Shang, L. Zhou, S. Sun, and L. Wang, " $\mathrm{BiVO}_{4}$ hollow nanospheres: anchoring synthesis, growth mechanism, and their application in photocatalysis," European Journal of Inorganic Chemistry, no. 29-30, pp. 4379-4384, 2009.
[38] G. Li, D. Zhang, and J. C. Yu, "Ordered mesoporous $\mathrm{BiVO}_{4}$ through nanocasting: a superior visible light-driven photocatalyst," Chemistry of Materials, vol. 20, no. 12, pp. 3983-3992, 2008.

[39] D. Ke, T. Peng, L. Ma, P. Cai, and K. Dai, "Effects of hydrothermal temperature on the microstructures of $\mathrm{BiVO}_{4}$ and its photocatalytic $\mathrm{O}_{2}$ evolution activity under visible light," Inorganic Chemistry, vol. 48, no. 11, pp. 4685-4691, 2009.

[40] K. I. Ishibashi, A. Fujishima, T. Watanabe, and K. Hashimoto, "Detection of active oxidative species in $\mathrm{TiO}_{2}$ photocatalysis using the fluorescence technique," Electrochemistry Communications, vol. 2, no. 3, pp. 207-210, 2000.

[41] Q. Xiang, J. Yu, B. Cheng, and H. C. Ong, "Microwavehydrothermal preparation and visible-light photoactivity of plasmonic photocatalyst $\mathrm{Ag}-\mathrm{TiO}_{2}$ nanocomposite hollow spheres," Chemistry-A Asian Journal, vol. 5, no. 6, pp. 14661474, 2010.

[42] X. Zhang, Z. Ai, F. Jia, L. Zhang, X. Fan, and Z. Zou, "Selective synthesis and visible-light photocatalytic activities of $\mathrm{BiVO}_{4}$ with different crystalline phases," Materials Chemistry and Physics, vol. 103, no. 1, pp. 162-167, 2007.

[43] J. Yu and A. Kudo, "Effects of structural variation on the photocatalytic performance of hydrothermally synthesized $\mathrm{BiVO}_{4}, "$ Advanced Functional Materials, vol. 16, no. 16, pp. 2163-2169, 2006.

[44] M. W. Stoltzfus, P. M. Woodward, R. Seshadri, J. H. Klepeis, and B. Bursten, "Structure and bonding in $\mathrm{SnWO}_{4}, \mathrm{PbWO}_{4}$, and $\mathrm{BiVO}_{4}$ : ione pairs vs inert pairs," Inorganic Chemistry, vol. 46, no. 10, pp. 3839-3850, 2007.

[45] G. Zhu and P. Liu, "Low-temperature urea-assisted hydrothermal synthesis of $\mathrm{Bi}_{2} \mathrm{~S}_{3}$ nanostructures with different morphologies," Crystal Research and Technology, vol. 44, no. 7, pp. 713-720, 2009.

[46] S. Liu, J. Yu, and S. Mann, "Spontaneous construction of photoactive hollow $\mathrm{TiO}_{2}$ microspheres and chains," Nanotechnology, vol. 20, no. 32, Article ID 325606, 2009.

[47] M. Oshikiri, M. Boero, J. Ye, Z. Zou, and G. Kido, "Electronic structures of promising photocatalysts $\mathrm{InMO}_{4}(\mathrm{M}=\mathrm{V}, \mathrm{Nb}, \mathrm{Ta})$ and $\mathrm{BiVO}_{4}$ for water decomposition in the visible wavelength region," Journal of Chemical Physics, vol. 117, no. 15, pp. 73137318, 2002.

[48] J. Yu, J. Xiong, B. Cheng, and S. Liu, "Fabrication and characterization of $\mathrm{Ag}-\mathrm{TiO}_{2}$ multiphase nanocomposite thin films with enhanced photocatalytic activity," Applied Catalysis B, vol. 60, no. 3-4, pp. 211-221, 2005.

[49] E. M. Patterson, C. E. Shelden, and B. H. Stockton, "KubelkaMunk optical properties of a barium sulfate white reflectance standard," Applied Optics, vol. 16, no. 3, pp. 729-732, 1977.

[50] N. Serpone, D. Lawless, and R. Khairutdinov, "Size effects on the photophysical properties of colloidal anatase $\mathrm{TiO}_{2}$ particles: size quantization or direct transitions in this indirect semiconductor?" Journal of Physical Chemistry, vol. 99, no. 45, pp. 16646-16654, 1995.

[51] J. Yu, S. Liu, and H. Yu, "Microstructures and photoactivity of mesoporous anatase hollow microspheres fabricated by fluoride-mediated self-transformation," Journal of Catalysis, vol. 249, no. 1, pp. 59-66, 2007.

[52] J. Yu, S. Liu, and M. Zhou, "Enhanced photocalytic activity of hollow anatase microspheres by $\mathrm{Sn}^{4+}$ incorporation," Journal of Physical Chemistry C, vol. 112, no. 6, pp. 2050-2057, 2008.

[53] H. Yu, J. Yu, S. Liu, and S. Mann, "Template-free hydrothermal synthesis of $\mathrm{CuO} / \mathrm{Cu}_{2} \mathrm{O}$ composite hollow microspheres," Chemistry of Materials, vol. 19, no. 17, pp. 4327-4334, 2007. 
[54] W. Cai, J. Yu, and S. Mann, "Template-free hydrothermal fabrication of hierarchically organized $\gamma$-AlOOH hollow microspheres," Microporous and Mesoporous Materials, vol. 122, no. 1-3, pp. 42-47, 2009.

[55] A. Zhang, J. Zhang, N. Cui, X. Tie, Y. An, and L. Li, "Effects of $\mathrm{pH}$ on hydrothermal synthesis and characterization of visible-light-driven $\mathrm{BiVO}_{4}$ photocatalyst," Journal of Molecular Catalysis A, vol. 304, no. 1-2, pp. 28-32, 2009.

[56] J. Yu, Y. Su, and B. Cheng, "Template-free fabrication and enhanced photocatalytic activity of hierarchical macro/mesoporous titania," Advanced Functional Materials, vol. 17, no. 12, pp. 1984-1990, 2007.

[57] J. Yu, W. Wang, B. Cheng, B. Huang, and X. Zhang, "Preparation and photocatalytic activity of multi-modally macro/mesoporous titania," Research on Chemical Intermediates, vol. 35, no. 6-7, pp. 653-665, 2009. 


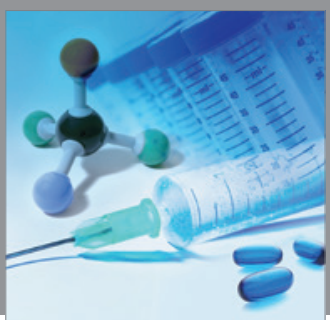

International Journal of

Medicinal Chemistry

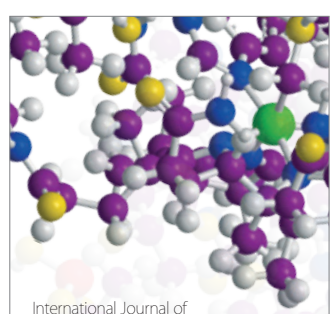

Carbohydrate Chemistry

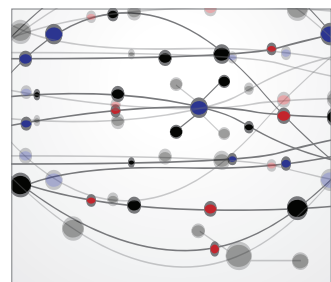

The Scientific World Journal
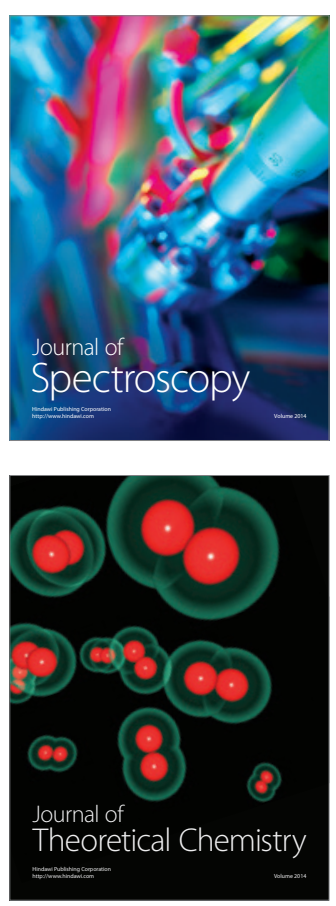
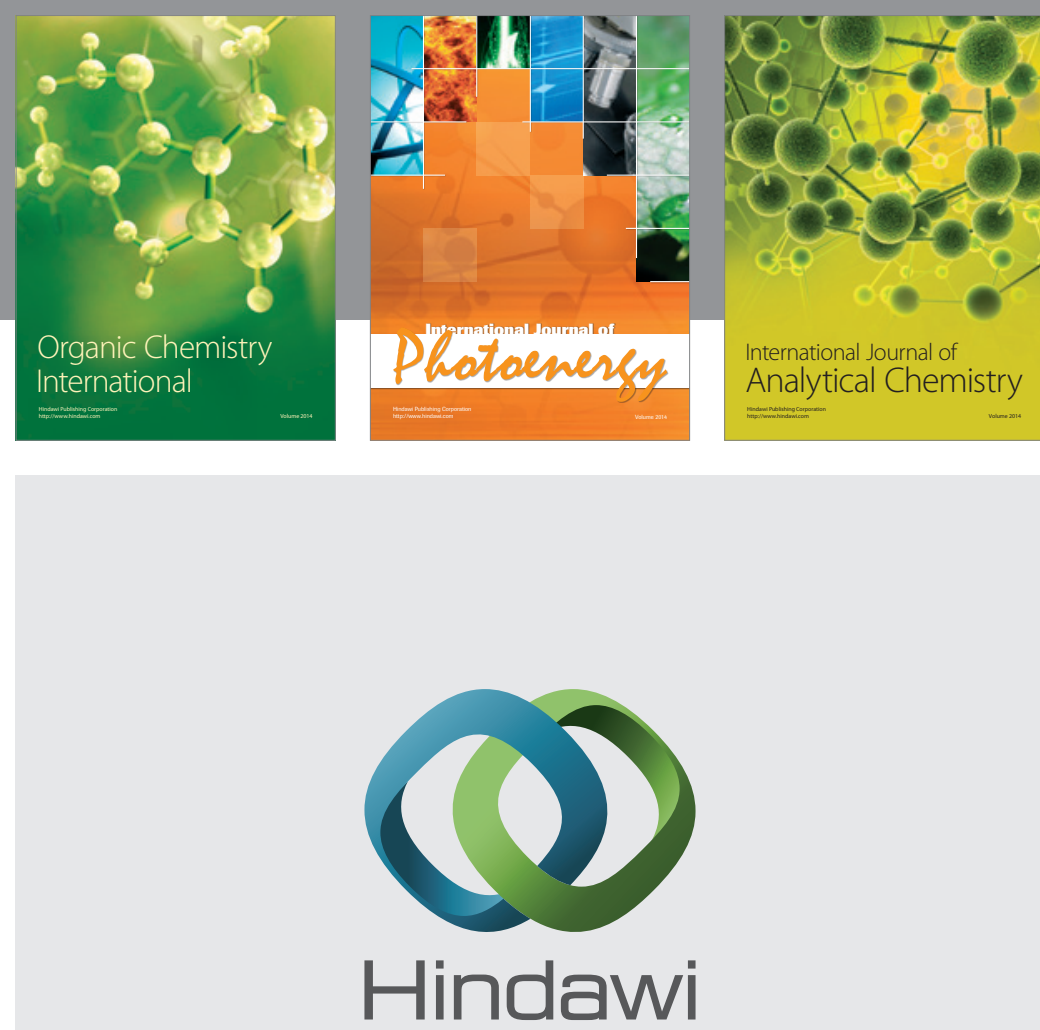

Submit your manuscripts at

http://www.hindawi.com
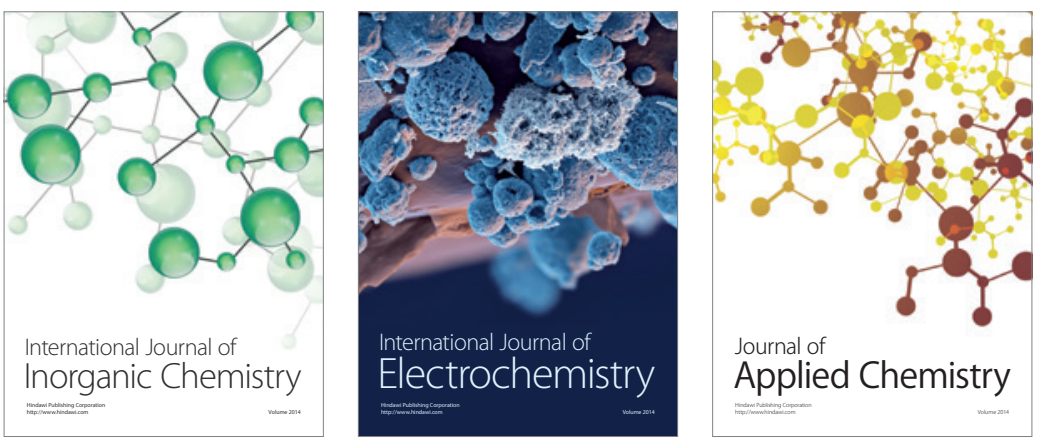

Journal of

Applied Chemistry
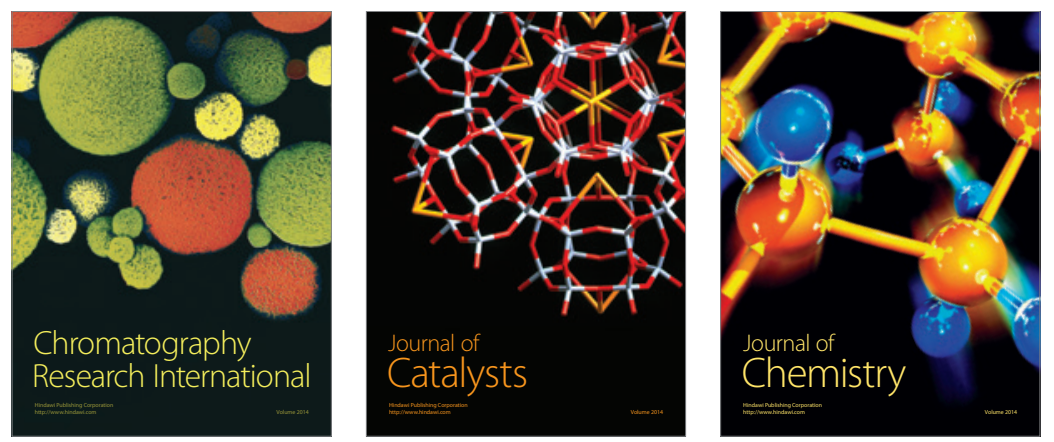
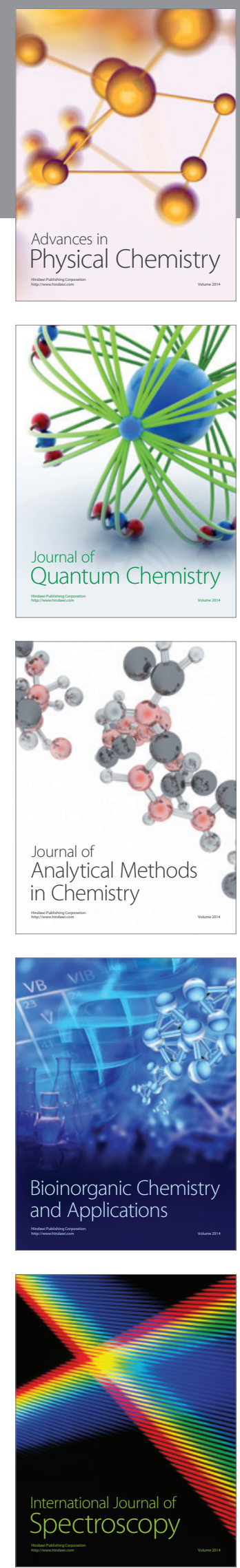